\title{
RÊGO, André Heráclito do; Família e coronelismo no Brasil: uma história de poder. São Paulo: Editora Girafa, 2008, 379p.
}

André Kron Zapani ${ }^{1}$

\footnotetext{
- Enviado em 30/09/2017

- Aprovado em 08/12/2017
}

O conceito de coronelismo, analisado academicamente de forma seminal pelo docente e renomado jurista Vitor Nunes Leal no clássico livro "Coronelismo, Enxada e Voto: o município e o regime representativo no Brasil", datado de 1949, se caracteriza, entre outros aspectos, pela superposição de formas desenvolvidas do regime representativo a uma estrutura econômica e social inadequada do Brasil, desde o início do século passado.

No entanto, após duzentos anos, esse conceito se faz atual e pertinente. Ele é necessário para interpretarmos as presentes e extemporâneas conjecturas sociais, políticas e econômicas do país. O patrimonialismo, o clientelismo, a apropriação do privado pelo público, a restrição de aspectos democráticos, o emprego da coerção física e psicológica em ilegalidades, a corrupção, a fraude eleitoral e a conduta seletiva dos mandões locais são atributos gerais desse sistema que tem um caminho epistemológico entremeado pelos campos sociológico, político e histórico.

Díspares foram as abordagens de sua validade temporal, de seu locus de atuação, do seu ethos, da inserção familial nesse sistema e do perfil do seu protagonista (o coronel). Sociólogos "brasilianistas", sociólogos brasileiros contemporâneos, historiadores, juristas e, recentemente, pesquisadores da área da comunicação se apropriaram desse sistema a fim de compreender o Brasil, suas possibilidades e suas complexidades, em diversas áreas do conhecimento.

Faz-se necessário também salientarmos que esse sistema tem uma abrangência territorial nacional - podemos citar como estados mais relevantes Bahia, Minas Gerais, São Paulo,

\footnotetext{
${ }_{1}$ Doutorando do Programa de Pós-graduação em Sociologia da Universidade Federal do Paraná. Mestre em Comunicação pela Universidade Tuiuti do Paraná. Integrante do Núcleo de Estudos Paranaenses. Email:andrekron@gmail.com
} 
Pernambuco, Goiás, Rio Grande do Sul - onde cada município tem as suas idiossincrasias, seus próprios protagonistas mas, seu habitus, em linhas gerais, de predicados semelhantes.

É nesse ínterim que essa resenha se propõe a analisar a obra "Família e Coronelismo no Brasil: uma história de poder", de André Heráclito do Rêgo, diplomata pernambucano e descendente direto de um dos principais e folclóricos coronéis da historiografia nordestina e nacional - o coronel Franco Chico Heráclito do Rêgo ou o comumente conhecido como Chico Heráclito.

O livro em questão, publicado em 2008, traz à tona o coronelismo nordestino, o mais "tradicional", destacando a territorialidade de Pernambuco, espacialidade essa em que viveram além de Chico Heráclito, os, também, coronéis José Abílio (no agreste) e Veremundo Soares e Chico Romão (no sertão). O destaque da obra de André Heráclito é a análise aproximada dos casos empíricos vividos pelo seu tio-avô Chico Heráclito e que foram documentados, bem como tiveram na maioria das vezes a participação solidária de sua família, sem desprezar os fundamentos histórico-metodológico do sistema coronelismo.

A abordagem de André Heráclito do seu objeto de pesquisa, e do sistema em que se circunscreve tal personagem, segue uma interpretação em uma perspectiva sociológica, semelhante à empregada por Maria Isaura Pereira de Queiroz, em "O mandonismo local na vida política brasileira", tida por André como a pioneira na análise do coronelismo em uma ótica social, analisando o coronel como um árbitro social, um definidor de regras, atenuando, assim, os enfoques de referenciais teóricos e históricos, tais como Raymundo Faoro, jurídicos, Victor Nunes Leal, e político-econômicos, Eul-Soo Pang, Amílcar Martins Filho.

É no campo sociológico, seguindo o pioneirismo de Queiroz, que a obra de André Heráclito proporciona outra grande contribuição para o estudo do coronelismo - de que forma a família ou a parentela, chefiada pelo mandão local, se inserem nesse complexo campo plural de forças podem ser indissociáveis? É possível estudarmos o conceito sistêmico em questão sem levar em conta a rede familial? É nesse contexto que o autor faz uma análise pertinente de que a família importa (e muito!), ela é uma peça vital para entendermos, desde as suas origens, as conjecturas local-regional-nacional da política brasileira, da rede de nepotismo nos diversos campos de poder no Estado (legislativo, executivo, judiciário) e em instituições privadas de poder simbólico (mídia, igreja, clubes de futebol, maçonaria). Esta relação indissociável entre família e coronelismo é que 
fez André Heráclito justificar, com pertinência, as escolhas de seu tio-avô e de sua genealogia para interpretar as relações hegemônicas entre os Heráclito do Rêgo e as estruturas de poder em diversas espacialidades, quer no município, no estado, na região nordestina e, inclusive, nacionalmente.

Da mesma maneira que o coronelismo teve construções sócio-políticas distintas para cada região do país, a construção familial, que adquiriu grande destaque na obra, seguiu as mesmas peculiaridades. Nesse escopo, André Heráclito faz um levantamento conceitual das diversas formas de construção de arranjo familiar, superando a clássica construção nuclear que vive em uma mesma morada, perpassando pela complexidade da parentela que vive solidariamente em distintos municípios, pelas querelas de amor e ódio entre seus integrantes, pelos laços consanguíneos de parentesco e inclusive pelas alianças e pelos vínculos espirituais.

O casamento endogâmico (mais corriqueiro no período pré-republicano e que havia conivência eclesiástica) ou exogâmico foram uma forma estratégica de se manter ou amplificar as alianças e os interesses das famílias. Podemos notar na obra os diversos arranjos sociais dos Heráclitos do Rêgo, inclusive a situação de família agregada, mas tendo sempre o coronel como o chefe dessa parentela, dessa família patriarcal.

"Sem família, o indivíduo não era [e continua sendo] nada" (RÊGO, p.46). Com esta citação importante do autor, por mim atualizada, podemos contextualizar esse sistema de interesses mútuos, que tem a família em seu core, e que envolve o público e o privado. Sem família, um proponente jamais ingressará no campo das classes dominantes, salvo raríssimos outsiders. 0 sociólogo Ricardo Costa de Oliveira² é categórico também ao afirmar que para se mapear esse quadro atual de poder, produto de um processo histórico-sociológico com poucas mobilidades sociais, devemos retroceder em um estudo genealógico a fim de procurarmos a família, o sobrenome, as relações matrimoniais e a mulher na estrutura familiar, destaca-se que esse último tópico foi pouco abordado pelo autor, para entendermos as classes dominantes atuais. Para se interpretar as conjunturas que oram se dispõem no cenário recente, devemos rastrear os arranjos familiais e suas sobreposições às estruturas de poder.

\footnotetext{
2 OLIVEIRA, Ricardo Costa de. Na teia do nepotismo - sociologia política das relações de parentesco e poder político no Paraná e no
} Brasil. Curitiba: Insight, 2012. 
A fim de exemplificar essa metodologia, proposta por Oliveira, que proporciona a criação de uma rede de mandonismo local, de clientelismo e de nepotismo, podemos extrair da obra de André Heráclito, algumas passagens, entre elas que o seu tio-avô foi eleito prefeito de Limoeiro em 1920, passando o cargo para seu irmão, em 1925, ano que Ernesto Pompílio de Albuquerque Rêgo tornou-se prefeito da recém-emancipada cidade de Floresta dos Leões e que seus irmãos Antônio e José, oficiais da Marinha, foram eleitos vereadores em Igarassu e em Vertentes, nos anos 1922 e 1928, respectivamente. Em seguida, Jerônimo Heráclito foi vereador e presidente da Câmara Municipal de Limoeiro entre 1935 e 1937. No âmbito familiar, inicia-se nesse período a união familiar entre os Vital do Rêgo, ramo genealógico dos Rêgo, e os Figueiredos, família dominante da política paraibana. Nessa mesma época, é fundada a Cooperativa Agropastoril, em Limoeiro, tendo como presidente fundador José Braz Pereira, o cunhado de Chico Heráclito, sendo sucedido por Francisco de Moraes Heráclito, seu filho. Paralelamente, foi fundada, em Campina Grande, a Companhia Ferro-Carril, empresa de bondes de burro, pelo seu tio Ernesto Pompílio do Rego.

Em 1951, foram eleitos Otaviano Heráclito Duarte, seu sobrinho, à vice-prefeitura e seu filho, José de Moraes Heráclito, à Câmara de Vereadores de Limoeiro. Em Surubim, elegeu-se o almirante Antônio Heráclito do Rego, seu irmão, como prefeito e seu sobrinho Jader, vereador. No mesmo ano, é inaugurada a Rádio Difusora de Limoeiro, pertencente a Francisco de Queirós, bem como aos seus irmãos, mesmos donos do jornal Diário da Noite, sobrinhos de Epitácio Pessoa, amigos de Chico Heráclito, além de serem cunhados de Miguel Braz Pereira de Lucena, irmão da esposa de Jerônimo Heráclito. A rede de nepotismo da família Heráclito do Rêgo tem pouquíssimas diferenças se comparada com a estrutura familial e as relações de clientelismo dos tempo modernos.

Outro exemplo que podemos observar na historiografia política de Chico Heráclito, e fazer um paralelo para a realidade vigente, foi a permissão de exploração de energia elétrica concedida pela prefeitura de Limoeiro ao sobrinho Otaviano Heráclito, por ocasião da chegada dessa benesse ao município.

Diversos foram os casos em que o privado e o público se entremearam, produzindo um panorama complexo de limites pouco evidentes e transparentes. Variados foram os casos em que as relações familiais e os interesses do Estado se sobrepuseram. É nesse escopo que a obra de 
André Heráclito contribui para os estudos sociológicos trazendo à tona não só a história familiar, mas disponibilizando exemplos empíricos documentados desses arranjos sociais e políticos atuais e de outrora, tomando como locus inicial o município de seu protagonista, espaço original de atuação dos coronéis, conforme descreveu Victor Nunes Leal em sua obra.

Cabe também destacar na obra de André Heráclito do Rêgo, na qual considero inclusive ser outro fator destoante entre os demais estudos sobre o coronelismo, é a correlação sumária desse conceito com a área da comunicação. Nos capítulos 19, 20 e 21, temas como a fotografia, o relacionamento com a imprensa e a propaganda são postos em discussão com pertinência. Paradoxalmente, a imagem do coronel na tradição literária cristalizou no imaginário nacional uma figura relativamente positiva. Ele é personagem frequente e humanizado dos cenários de programas televisivos e da teledramaturgia pós-1985 que associa seu perfil à vida política das pequenas cidades brasileiras. O próprio Chico Anysio criou um personagem, uma caricatura irreverente de Chico Heráclito o Coronel Limoeiro.

O chefe local do sistema em análise é um senhor um tanto arcaico, mas valoriza a família, nunca é o vilão, é sentimental e muitas vezes reproduz o imaginário patriarcal. Segundo a pesquisadora da UFRJ Suzy dos Santos "ele é quase um avô da gente, um senhor meio atrasado, mas sempre um grande amante, sempre muito ligado à família ${ }^{3 \prime}$. Nesse aspecto da reprodução do imaginário coronelístico, o mandão local de André Heráclito não foge às demais pesquisas, corroborando com a visão mais romantizada e humanizada. Basta analisar o corpus fotográfico selecionado pelo autor entre as páginas 210 e 245 .

No tocante ao acesso à imprensa, Chico Heráclito soube utilizar o poder simbólico da mídia impressa e radiofônica de sua época para difundir sua imagem e, principalmente, persuadir seus públicos a fim de obter vantagens eleitorais para e si e alheios de sua indicação. A imprensa foi a intermediária, ou melhor, foi de certa forma uma das instituições que propiciou as barganhas entre o particular e o governamental, mantendo um dos alicerces da estrutura de sustentação do coronelismo - o voto do "rebanho" eleitoral. Ela foi instrumentalizada por Chico Heráclito. O acúmulo do capital midiático proporcionou uma manipulação de mensagens diretas e subliminares que o mandão direcionava aos seus interlocutores.

3 Publicado em "Coronelismo 2.0: os novos rumos da aliança entre política e mídia no Brasil". Disponível em:https://theintercept.com/2017/12/11/coronelismo-2-0-os-novos-rumos-da-alianca-entre-politica-e-midia-no-brasil/. Acessado em: 18 dez 17 
Por fim, vários autores divergem sobre o prazo de validade do coronelismo. Diversos foram os marcos temporais estipulados para sua extinção. Outros, incluindo André Heráclito, seguem uma linha de que eles continuam a existir. Eles se remodelaram, se adaptaram aos novos tempos, podem inclusive dentro de suas áreas de influência se tornar agentes de desenvolvimento político e econômico. Todavia, esse tópico requer uma análise mais aprofundada, a fim de não incidirmos na generalização e em uma visão rasa e restrita desse conceito tão importante e tão relevante para a manutenção das relações assimétricas dos poderes econômico, político, social e midiático de nossa sociedade bastante influenciada pelas estruturas de outrora. A interpretação do status quo da sociedade atual, obrigatoriamente deve passar pelas discussões atinentes ao coronel e, principalmente, pelo seu sistema de sustentação de seu protagonista com as representações institucionais do Estado - o coronelismo.

\section{REFERÊNCIAS}

LEAL, Victor Nunes. Coronelismo, Enxada e Voto: o município e o regime representativo no Brasil. São Paulo: Companhia das Letras, [1949] 2012

OLIVEIRA, Ricardo Costa de. Na teia do nepotismo - sociologia política das relações de parentesco e poder político no Paraná e no Brasil. Curitiba: Insight, 2012.

QUEIROZ, Maria Isaura Pereira de. 0 mandonismo local na vida política brasileira. São Paulo: Universidade de São Paulo, 1969.

RÊGO, André Heráclito do; Família e coronelismo no Brasil: uma história de poder. São Paulo: Editora Girafa, 2008, 379p. 